\title{
Editorial
}

\section{LOS CONCURSOS UNIVERSITARIOS O JUICIOS SIMULADOS EN EL MARCO DE LA ENSEÑANZA DEL DERECHO}

\author{
Andrea Alarcón Peña \\ Juan Carlos Villalba Cuellar
}

DOI:

Desde hace un buen tiempo para acá es frecuente que los estudiantes y profesores, los primeros en calidad de concursantes y los segundos en calidad de tutores, participen en concursos que organizan universidades y prestigiosas organizaciones internacionales. Estos concursos, también denominados bajo el término en inglés "moot court", consisten en juicios simulados en los que varios equipos, frente a un caso ficticio planteado, deben presentar, a través de varias etapas, una primera parte escrita y una segunda oral, la defensa y alegatos que son clasificatorios, para llegar a una final en la que se sabrá qué equipo se corona campeón o ganador del juicio - jurídicamente hablando-. El concurso exige superar varias etapas en las que se evalúan las competencias escritas, comunicativas y propositivas de los participantes. La preparación es intensa y el nivel de exigencia alto. Se pone en juego la capacidad de los estudiantes para poner en práctica todo aquello que han aprendido a lo largo de su formación. Los jurados o jueces son prestigiosos juristas y profesores expertos en los temas, provenientes de las más diversas latitudes.

Dedicaremos las siguientes líneas a examinar las ventajas y desventajas que la implementación de esos concursos trae en la enseñanza y aprendizaje del Derecho. En un sector de la academia, este tipo de prácticas son calificadas como "moda", es decir, como una tendencia pasajera que corresponde a cierto tipo de universidades que, amparadas en su prestigio, quieren consolidar más "trofeos" en su palmarés de éxitos. La consecución de un premio en- riquecerá los anaqueles y acreditará la fortaleza académica en un área específica de formación. Importante papel ocupan, entonces, los profesores, maestros en el área, los formadores y capacitadores de los estudiantes. Eso, evidentemente, el tiempo lo dirá, aunque lo verdaderamente importante es la verificación del aporte que este tipo de experiencias aportan a la formación de los profesionales del Derecho.

Lo primero a rescatar es que todo ejercicio que desarrolle y potencialice las competencias que necesita un profesional debe ser reconocido como un aporte a la enseñanza, y los concursos interuniversitarios lo hacen. Para nadie es un secreto que la capacidad de análisis, la síntesis y el buen manejo de la oratoria son imprescindibles en un profesional del Derecho, y la participación de los estudiantes en esos ejercicios que simulan un juicio contribuyen poderosamente al desarrollo de las mismas. Por lo tanto, de entrada, es positivo que tanto las universidades como profesores y estudiantes se animen a participar en ellos.

Además, el hecho de participar, interactuar con estudiantes de otras universidades e inclusive perder frente a ellos les permitirá a los estudiantes aprender y desarrollar habilidades en el manejo de situaciones difíciles, mejorar su nivel de tolerancia frente a la pérdida y, sobre todo, interactuar con estudiantes de otras facultades, con formación y orientación diversa, conocer puntos de vista diversos, aprender del error $y$ cualificar las fortalezas. Todo esto permitirá sin duda que el estudiante comience a proyectarse profesionalmente en un ámbito especializado. 
Algunos agregarian que esto de paso contribuye al prestigio de la facultad de derecho y de la universidad a la que pertenecen. No obstante, debemos acotar varias cosas. Este tipo de ejercicios no debe restringirse a los estudiantes que se interesen en participar en dichos concursos, dado que terminaría siendo cosa de unos pocos y se perdería una oportunidad para el resto de los estudiantes. Es importante advertir cómo en diversas versiones los asistentes guardan absoluta identidad, y el nivel de rotación y la posibilidad de apertura a otros interesados resultan limitados.

En ese sentido, las universidades deberían promover internamente $y$ de manera constante ejercicios de este tipo que le permitan a todos los estudiantes participar y mejorar sus competencias para el ejercicio profesional. Nótese que porcentualmente es muy bajo el número de universidades que participan en esos concursos $y$, más allá de eso, lo que importaría es que aquellas facultades que todavía no lo consideran útil, lo vayan implementando así sea internamente como didáctica para el aprendizaje del derecho.

En segundo lugar, las universidades deben guardar la mesura frente a este tipo de ejercicios, no se trata de ganar a toda costa, de acumular premios y posar para las fotos porque sí; la finalidad de estos ejercicios es formativa, el aprendizaje y la experiencia adquirida constituirá el fin esencial de la participación. La victoria será un elemento adicional, meritorio, por supuesto, pero no el fin en sí mismo. Por lo tanto, si el equipo conformado para una versión del concurso no es tan bueno, finalmente lo importante será que esos estudiantes acumulen experiencias y aprendizajes que les permitan ser mejores profesionales.

Lo mismo pasa con los profesores tutores, al cabo de un tiempo la repetitividad del ejercicio los desgasta y nuevas generaciones de profesores debieran estar animándose a llevar equipos a los concursos. La idea de fondo es que el ánimo competitivo no desdibuje en ningún caso la finalidad pedagógica de los concursos. Se han escuchado profesores y estudiantes decepcionados por la dinámica de algunos de estos concursos, que a veces rayan en la parcialidad, lo cual sin duda es un riesgo humano de este tipo de ejercicios, y esto ha sucedido tal vez porque el ánimo competitivo ha permitido que se desvien de su intención inicial. No es lo deseado. En ese orden de ideas, queremos rescatar que los concursos interuniversitarios de juicios simulados son un aporte en la medida en que los educadores comprendamos que estos giran en torno a los estudiantes y que los concursos más que un fin son un medio para que los futuros abogados sean más competentes en su ejercicio profesional. Así las cosas, no dejemos que se vuelva una moda y tampoco permitamos que, si se quedan como práctica pedagógica, como debería ser, terminen reflejando las vicisitudes e imperfecciones de la realidad en la práctica del derecho. 